\title{
Navegando Nuvens: Notas sobre a prática dramatúrgica e os procedimentos de preparação para a escrita
}

\author{
Camila Damasceno Silva \\ Universidade Estadual de Campinas - UNICAMP, Campinas/SP, Brasil \\ E-mail: camila.damasceno@outlook.com
}

\section{Resumo}

Este texto apresenta-se como um apanhado de reflexões e questionamentos no campo da dramaturgia, com ênfase nos processos de criação coletivos nas artes da cena e nos procedimentos de preparação para escrita dramatúrgica - tema raramente abordado em textos que se debruçam sobre tal prática. Dividido em onze fragmentos, passa pelo diálogo com Antônio Gonçalves Júnior (Duran), André Lepecki, Eleonora Fabião e Hans Ulrich Gumbrecht, a fim de traçar caminhos possíveis para a prática dramatúrgica que não se limita à criação textual. Considerando aspectos caros à performatividade, traça implicações em um fazer artístico que se contrapõe às ideias "fetichizadas" envolvidas em todo espectro de profissões que lidam com práticas de escrita. Serão, ainda, relatados processos e procedimentos experimentados pela autora em sua prática dramatúrgica. Resultado preliminar de projeto de pesquisa que propõe uma análise de práticas de dramaturgia no contexto contemporâneo, as notas se apresentam como propostas de outros modos de estar, produzir, trabaIhar e se relacionar com as pessoas e com as materialidades como necessárias à prática de dramaturgia - que não necessite negar o texto ou a produção textual e que seja composta em processo coletivo.
This text presents itself as a collection of reflections and questions in the field of dramaturgy, with an emphasis on the collective creation process in the performing arts and in the procedures of preparation for dramaturgical writing - a theme rarely addressed in texts that focus on this practice. Divided into eleven fragments, it goes through a dialogue with Antônio Gonçalves Júnior (Duran), André Lepecki, Eleonora Fabião and Hans Ulrich Gumbrecht, in order to outline possible paths for dramaturgical practice that is not limited to textual creation. Considering aspects of performativity, it traces implications in an artistic practice that is opposed to the fetishized ideas involved in the whole spectrum of professions that deal with writing practices. Process and procedures experienced by the author in her dramaturgical practice will also be reported. Preliminary result of a research project that proposes an analysis of dramaturgical practices in the contemporary context, the notes are presented as proposals for other ways of being, producing, working and relating to people and materialities as necessary to the practice of dramaturgy - that does not need to deny the text or textual production and that is composed in a collective process.

Keywords

Scene. Dramaturgy. Preparation for Writing. Creation Process. 


\section{Primeiras considerações}

Boa parte da formação de atores e atrizes se concentra no desenvolvimento de uma aptidão e uma prontidão para acessar estados psicofísicos específicos. Escolas, métodos, práticas orientais ou de povos originários, treinamentos, aquecimentos, muitas são as maneiras de se preparar para criar e estar na cena. No entanto, quando falamos da prática dramatúrgica, da elaboração de uma escritura seja para a cena, seja na cena, ou ainda, com a cena, o tema é raramente abordado. Corroborando uma imagem "fetichizada" de escritores lidando com seus demônios, musas e inspirações na solidão de seus quartos mal iluminados no meio da madrugada, muitos dramaturgos e dramaturgas - assim como seus pares que se incumbem das demais áreas do fazer cênico - seguem lidando com seus escritos como uma expressão genuína de suas subjetividades iluminadas.

Os processos de criação coletivos fundaram, nas últimas décadas, a figura do dramaturgista e é vasta a produção científica que se põe a esmiuçar quais seriam as suas atribuições e competências necessárias, para além dos manifestos em defesa da existência dessa figura nos coletivos criadores. Articulou-se, então, o que seriam duas práticas distintas, ficando a cargo do dramaturgista um campo muitas vezes borrado entre seu ofício e o do encenador ou coreógrafo. A pouca clareza sobre a prática da dramaturgia nesses termos gerou (e ainda gera) inúmeros conflitos em processos criativos - apesar de relatos de sucesso nesse tipo de parceria. Concomitantemente, escrever um texto para ser encenado, ou o que comumente indicamos como o ofício do dramaturgo ou dramaturga, permanece uma prática de escrita aceita e consolidada. A escrita solitária da dramaturgia, para além dos exercícios formais, costuma se estabelecer como potente atividade imaginativa para quem escreve os textos; daí a maior parte dos conflitos entre dramaturgos e encenadores uma vez que a obra cênica se apresenta "de pé".

Não são incomuns as trocas de acusações em que encenadores e atuantes afirmam suas leituras, suas interpretações da obra textual, contra escritores que bradam que "aquilo não é o que eu escrevi!". Mais comum nas oficinas e escolas de teatro, mas não raro no campo profissional e entre adultos, essas trocas de insultos públicas são bons sinais de que a distância do texto para a cena não é somente a da palavra lida para a palavra falada.

Esse preâmbulo, contudo, pode parecer datado. Afinal, o texto não é o centro do teatro contemporâneo desde meados do século passado. Mas por que, então, todo o pensamento em torno da dramaturgia, hora ou outra, esbarra na tentativa de retraçar suas definições e os limites da prática nos processos de criação cênica? Pesquisar, fazer e escrever sobre dramaturgia parece um eterno retorno à pergunta primeira: o que é dramaturgia?

\section{Algumas questões}

Dramaturgia é somente a construção semântica de um trabalho cênico? O processo de criação que se encarrega de criar uma dramaturgia é um processo que busca somente construir o discurso da obra? Qual sua conexão com os processos criativos que se desenrolam a partir dos corpos e das demais materialidades da cena? Quais as diferenças entre fazer dramaturgia e escrever um texto para ser falado diante de um público? O que está em jogo quando a dramaturga assume um modo de estar nos processos que abarca outras dinâmicas além da criação de uma materialidade textual? Quais as implicações de uma dramaturgia que se propõe enquanto propulsora e articuladora de processos, discursos, imagens poéticas, sentidos e sensações?

A dramaturgia tem se configurado em distintos modos de atuação, expandindo seu conceito para além da tradicional ideia de literatura dramática. As interseções teatrais com campos como a dança e a performance geraram diversas implicações no fazer dramatúrgico desde o início do século passado, impulsionando o desdobramento de tal prática em múltiplas direções. Muitos também foram os teóricos, artistas e artistas-pesquisadores que se debruçaram sobre este tema nas últimas décadas. Os trabalhos de Eleonora Fabião, Hans Thies Lehmann, Jean-Pierre Sarrazac, 
Jean-Pierre Ryngaert, Joseph Danan, José António Sánchez, Luiz Alberto de Abreu, Óscar Cornago, Josette Ferál e tantos outros ajudam a dar a dimensão da abertura para a qual o campo da dramaturgia foi lançado. Fala-se até em uma pós-dramaturgia que, de certa forma, dê conta de múltiplos aspectos do processo criativo dramatúrgico, até as possibilidades de materiais e materialidades que seja capaz de gerar.

Falar de dramaturgia sem se limitar ao discurso ou à narrativa é um dos pontos centrais nessa discussão. O que implica no fazer dramatúrgico considerar os aspectos perceptivos que não dependem de - ou necessariamente denotam - uma interpretação?

Para Hans Ulrich Gumbrecht, vivemos no ocidente, hegemonicamente, um momento histórico no qual o predomínio de uma "cultura de sentido" é absoluto, tendo em sua base a dicotomia sujeito x objeto; na qual o sujeito se vê externo ao mundo e produz seu conhecimento através do ato de interpretação. Enquanto na cultura de sentido a auto referência humana é o pensamento, em uma "cultura de presença", tal auto referência é o corpo. O sujeito se vê então como parte de uma cosmologia e o conhecimento é "conhecimento revelado", através de "eventos de auto revelação do mundo". No entanto, estas definições não se dão de forma totalizante e mesmo em uma cultura predominantemente de sentido, os fenômenos de presença, ainda que efêmeros, se fazem em forma de "efeitos": efeitos de presença (GUMBRECHT, 2010). As artes seriam então o campo fértil para as oscilações entre o sensível e o cognoscível, entre as percepções corpóreas e a interpretação. Ainda segundo Gumbrecht, "podemos dizer que a tensão/ oscilação (entre os dois efeitos) dota o objeto de experiência estética de um componente provocador de instabilidade e desassossego" (Idem, 2010, p. 135).

O certo desejo de presença seria então como uma reação ao mundo cotidiano dominado pela dimensão interpretativa, no qual as experiências estéticas se mostram campos férteis para a coexistência de efeitos de sentido e efeitos de presença. "Em vez de termos de pensar sempre e sem parar no que mais pode haver, às vezes parecemos ligados num nível da nossa existência que, pura e simplesmente, quer as coisas do mundo perto da nossa pele" (Ibidem, p. 135).

\section{Instabilidades e Desassossegos}

Aquilo para o qual eu não consigo dar uma explicação, aquilo para o qual eu não tenho palavras, o que todas as palavras do mundo reunidas de todas as formas possíveis ainda assim não dariam conta... Aquilo que não vira narrativa, que não se transforma em discurso, que não exprime uma posição... Aquilo que eu respiro e sinto no ar e te vejo e você também sente e nós juntos sabemos o que é, mesmo que não haja palavra possível, explicação cabível... Aquilo que não é a expressão de algo, mas a materialização de algo em si... Que não é predominantemente representação, mas presença... Aquilo que se estabelece como uma atmosfera, que se faz presente com uma complexidade imanente, é da conta da dramaturgia?

\section{Mais algumas questões}

Qual a diferença entre ser dramaturga e ser cronista, romancista, roteirista? Dramaturga ou poetiza? Dramaturga ou jornalista? O que "escrever para teatro" implica?

\section{Relatando uma experiência}

Eu me encaminhava para o quarto final do curso de formação em dramaturgia na SP Escola de Teatro, em um projeto no qual, pela primeira vez, os coletivos de aprendizes tinham liberdade de escolher seus parceiros de criação e a linguagem teatral que gostariam de experimentar. Desde o princípio, as questões relativas à performatividade e ao teatro performativo se mostravam intrigantes o suficiente para que nosso grupo se empenhasse nesse caminho. Naquele processo de criação, no qual contava com um número considerável de colegas com funções nas principais áreas necessárias à produção teatral ${ }^{1}$ e com

\footnotetext{
1 A SP Escola de Teatro é um Centro de Formação localizado na cidade de São Paulo, que, dentre outros cursos, oferece formação continuada de dois anos nas áreas de direção, dramaturgia, atuação, humor, cenografia e figurino, técnicas de palco, sonoplastia e iluminação.
} 
o acompanhamento de profissionais que atuavam como nossos formadores ${ }^{2}$, decidimos coletivamente que não partiríamos de um tema específico, mas começaríamos com práticas que pudessem apontar encaminhamentos para o projeto a partir dos desejos de cada um dos integrantes daquele coletivo. Estávamos dispostos a descobrir naquele processo o que é e como é fazer teatro performativo em grupo.

Eu dividia a dramaturgia com mais um colega, assim como a direção também era feita por uma dupla de aprendizes. O mais comum no início do processo era que nós da dramaturgia passássemos todo o ensaio observando o que diretores e atores faziam, buscando nas imagens, palavras, sonoridades, gestos e movimentos que surgiam, alguma coisa com a qual nos apegar. Nesse momento, atuávamos como o que, limitadamente, era entendido como dramaturgismo; executando tarefas pouco criativas e mais próximas de uma observação crítica do processo, tal como define Gonçalves Júnior:

Dentre as tarefas abrangentes executadas pelo dramaturgista, consideramos que a dimensão crítica se instaura não apenas na pesquisa e seleção de materiais teóricos, históricos e conceituais, mas sobretudo na participação como observador e interlocutor analítico em busca por "consistência" do trabalho. Essa busca é a possibilidade de plasmar poeticamente (em todas as áreas de criação e em seus materiais) alguns reflexos da complexidade do processo de criação em relação e, simultaneamente, em atrito com as contradições de seu tempo histórico e contexto sócio-espacial, por meio da percepção que compreende um estado de receptividade ativa, capaz de assimilar a obra como ela própria quer ser. (GONÇALVES JÚNIOR, 2019, p. 40).

Éramos, então, dois observadores externos que dialogavam praticamente só com os diretores e tomavam notas para possíveis encaminhamentos

2 Uma vasta gama de profissionais renomados do teatro paulistano já passou pela escola enquanto formadores desde 2010, quando foi fundada, tais como integrantes do Teatro da Vertigem, Teatro de Narradores, Os Satyros, Os Parlapatões, dentre outros. discursivos para o trabalho e indicações de referências artísticas e teóricas para o processo. Nossa participação era um tanto tediosa até então. $\mathrm{Na}$ condição de aprendizes, dando nossos primeiros passos em processos criativos coletivos, sentíamos que não estávamos colaborando muito com o andamento do trabalho ou fazendo algo muito diferente do que a dupla da direção fazia (com o agravante de que não éramos nós, dramaturgos, que propúnhamos os procedimentos e seus disparadores). Inquieta com uma posição passiva, passei a questionar se poderíamos trazer materiais textuais escritos por nós a partir das observações dos ensaios para serem utilizados na elaboração das práticas propostas pelos diretores aos atores do grupo. Passamos então a transformar nossa observação e "garimpo", afetando nossa disposição em olhar para aquelas práticas em busca de algo que nos afetasse e nos impulsionasse para a escrita. Começamos a desenvolver pequenos textos individualmente e levá-los aos diretores, que, a partir deles reelaboravam procedimentos de criação cênica com os atores. Sonoplastas e iluminadores passavam a também experimentar intervenções durante a realização das práticas de atuação. Começávamos aí a desenvolver um modo específico de criação para aquele coletivo. Os materiais textuais que chegavam não obedeciam a lógica da montagem ou da relação representacional calcada no texto, mas eram disparadores poéticos para procedimentos de criação cênica.

Ainda assim, a separação da prática da escrita do momento da prática de criação coletiva do grupo me incomodava. O deslocamento temporal e espacial da criação dramatúrgica parecia não fazer sentido em um processo onde escolhíamos criar juntos. Foi então que, durante um dos ensaios, resolvi transformar o que seriam minhas notas de observação em material textual para a cena. Queria experimentar o que seria escrever durante a cena: me colocar em produção textual a partir do fluxo de criação cênica que se desenrolava ao meu redor, a partir dos estímulos sensoriais que aquelas práticas geravam. Experimentei então, pela primeira vez, es- 
crever com a cena, no momento e no espaço em que atuantes, iluminadores, sonoplastas, diretores - e nós, dramaturgos (por que não?) - criávamos juntos.

A primeira vez que escrevi na cena e na sequência compartilhei aquele fragmento de texto que, imediatamente retornou para a experimentação cênica transformando-a, se configurou como uma experiência marcante em minha ainda curta trajetória de prática dramatúrgica. Naquele dia, senti pela primeira vez que estava criando de forma coletiva, com meus companheiros de trabalho, respeitadas suas funções no processo e, acima de tudo, de forma incrivelmente dependente da qualidade de relação que estávamos sendo capazes de criar sob aquelas condições de produção. Ali, percebi que meu trabalho sempre estaria indelevelmente atrelado àqueles que compartilham comigo cada processo e, ainda, que a qualidade ou potência do que posso produzir não diz respeito só a mim, mas principalmente à forma como me coloco também em jogo com aquelas pessoas. Meu trabalho depende do deles - atores, diretores, iluminadores, sonoplastas, cenotécnicos, etc - não para que eu veja materializado em cena o que visualizei na minha imaginação criante, no meu processo individual, mas para me impulsionar na própria prática da escrita, para que eu seja capaz de criar COM eles.

A intensidade de tal experiência e o desenrolar do processo no qual todos nos sentíamos parte imprescindível na criação, sem que a ideia de autoria ou as qualidades do trabalho fossem avaliadas separadamente, individualmente, gerou uma quantidade enorme de questionamentos para mim a respeito do ofício no qual estava me dispondo a investir. Escrever na cena ou com a cena passou a exigir de mim uma outra postura nos ensaios, uma outra forma de participação, de observação, de abertura perceptiva que extrapolasse a tentativa de me apegar a pequenas coisas que pudessem compor um discurso.

Até hoje, aquele trabalho foi o evento cênico mais calcado na partilha de intensidades sinestésicas do qual participei enquanto co-criadora. Nosso experimento Você devia ter fechado a porta, não dispunha de uma linearidade narrativa ou mesmo de uma fábula, ainda que recortada, fragmentada. Ele era em si composição com fragmentos gestuais, sonoros, textuais... O fluxo de imagens, sonoridades, palavras, movimentos, gestos era a dramaturgia da obra, que não estruturava um discurso, que não solicitava ao espectador que a interpretasse, mas que se permitisse experimentar os fluxos perceptivos, as fricções entre as materialidades da cena, incluídos aí os materiais textuais. Era um convite a deslocamentos sensório-perceptivos, que não excluíam uma camada de sentido, mas, contudo, invertiam a ênfase comumente dada ao discurso da obra para suas camadas invisíveis e indizíveis.

A dimensão de que o trabalho existia em potência de ocasionar tais deslocamentos perceptivos só foi possível depois do contato com o público, em mais de uma sessão e o retorno comum no ambiente da escola, vindo tanto de profissionais que atuavam em nossa formação, quanto de colegas aprendizes. Naquele processo, percebi o quanto me dava mais prazer trabalhar desta forma do que escrever textos para serem encenados. Para tanto, precisaria aprimorar cada vez mais o modo de fazer parte dos processos criativos coletivos. Precisaria desenvolver maneiras de compartilhar o espaço de criação com uma outra atitude, algo que, posteriormente, entendi como "estado de presença", associado ao que André Lepecki chamou de "errância como método". Segundo Lepecki,

[...] a errância deverá ser compreendida não como uma busca por erros, um privilégio dos equívocos ou, ainda, uma apologia à falha como método (...), mas no seu sentido etimológico mais forte: errar como derivar, perder-se, extraviar-se. Mas permitam-me somar a esses modos de navegar sem bússola um afeto que chamaria persistência ética; um desejo de seguir sem precisar saber para onde nos dirigimos, de modo que juntos possamos construir aquilo que não sabemos o que pode ser. (LEPECKI, 2016, p. 66).

Essa persistência ética à qual Lepecki se refere é a chave para um modo de criação verdadeiramente coletivo, no qual o sentido de autoria muda de 
eixo, respeitando-se as qualificações e disposições de cada indivíduo participante do processo criativo. A "assinatura" da dramaturgia não muda de nome, como sua prática também não atropela aquilo que é incumbência de diretores, encenadores e coreógrafos. No entanto, esta "outra" maneira de estar nos processos certamente requer outras preparações para a prática da dramaturgia, seja nos momentos efetivamente de escrita, seja na proposição ou na composição das materialidades cênicas surgidas durante o trabalho. Assim, algumas questões relacionadas à disposição e preparação para o fazer dramatúrgico surgem, tais como: quais são os aspectos psicofísicos que afetam ou podem afetar a criação dramatúrgica e a produção textual destinada a uma obra cênica? Como determinadas práticas permitem acessar estados psicofísicos específicos e assim potencializar determinados tipos de escritura?

\section{Algumas pistas}

Eleonora Fabião diz acreditar ser de grande valia a experimentação de práticas psicofísicas baseadas na tradição da performance para os artistas da cena em geral (FABIÃO 2008, p. 239), no entanto, tais experimentações parecem estar sempre associadas àqueles que tem na relação do corpo com a cena sua matéria principal de trabalho (atuantes e dançantes). A dicotomia corpo e mente parece ter separado as práticas cênicas entre aqueles que agem em cena e aqueles que produzem o discurso da cena. Assim, restaria a dramaturgos, dramaturgas e encenadores as funções próprias à mente: pensar, escrever, ordenar, compor. Enquanto que aos atuantes, o trabalho físico, psicofísico, corporal. Mesmo diante de um cenário que discorre pela superação destas crenças dicotômicas, nos estudos sobre dramaturgia é rara a associação entre estados psicofísicos e prática dramatúrgica, ou ainda, experimentações corporais, físicas, perceptivas e práticas de escritura cênica - ainda que o contrário seja mais do que válido em inúmeros processos criativos onde atuantes produzem, dentre outras coisas, materiais textuais.

Por que não falamos (ou falamos tão pouco) so- bre práticas de preparação para a escrita dramatúrgica? Quais as especificidades de uma escrita cênica que a distingue dos demais processos criativos que se baseiam no ordenamento de palavras? Quais são as implicações nas práticas de escrita que a cena impõe?

\section{Navegando Nuvens}

André Lepecki diz dos processos de criação em dança (pós anos 80 do século passado) que estes passaram a se estruturar partindo de proposições de questões abertas sugeridas pelos coreógrafos e respondidas provisoriamente pelos bailarinos; de forma que o uso das capacidades e singularidades daqueles corpos sejam privilegiadas em detrimento de um "arco dramático" (LEPECKI, 2016, p. 74). Nesse contexto,

[...] o trabalho do dramaturgista parte dessas zonas de indeterminação, dessas nuvens e vapores já povoados por elementos muito concretos que compõem o campo heterogêneo de dispersão específico de cada singularidade autoral. Nesse campo-nuvem, material e específico, estão coreógrafo, bailarinos, colaboradores artísticos e dramaturgista tentando seu melhor para não se tornarem somente vapor. Em outras palavras, a dramaturgia da dança opera num campo de desunidade que, entretanto, permanece específico e exige coerência. Essa coerência parte da materialidade granulada das ações, pensamentos, passos, gestos, objetos, acessórios, figurinos, tempos e ritmos que cada bailarino, cada objeto, cada lugar exala, invoca e, coletivamente, reúne num plano de composição. (LEPECKI, 2016, p. 74).

O trabalho de proposição e composição de materialidades mostra-se uma especificidade do fazer dramatúrgico. Uma prática que, não necessariamente, precisa se limitar à composição de palavras, discursos, campos semânticos. A imagem de um "campo-nuvem" heterogêneo e material sugerida por Lepecki, no qual a prática da dramaturgia encontra sua matéria primeira em processos de criação coletivos como o relatado acima, sugere a necessidade do dramaturgo (ou dramaturgista) desenvolver capacidades específicas para capturar as densidades e sutilezas que compõem esse campo. 
Uma nuvem é um amontoado de gases, mais ou menos densa, mais ou menos translúcida, mais ou menos carregada de água. Uma matéria que sobrevoa nossas cabeças e pode nos encobrir a visão; portanto, não se trata de desenvolver um procedimento único, padrão para lidar com todo e qualquer processo-nuvem. Há que se estar constantemente descobrindo as práticas mais oportunas para lidar com cada campo, com cada coletivo, com cada pessoa, não apenas como um observador privilegiado, mas como alguém completamente implicado nesta mesma nuvem.

Tal como em Procession, de Shana e Robert ParkeHarrison, àquele que se propõe a criação dramatúrgica em processos coletivos de criação, cabe estar atrelado ao campo-nuvem das materialidades cênicas que surgem no processo, sem perder de vista o chão para o qual pendem seus anzóis.

\section{Figura 1 - Procession, Robert} e Shana ParkeHarrison, 2004.

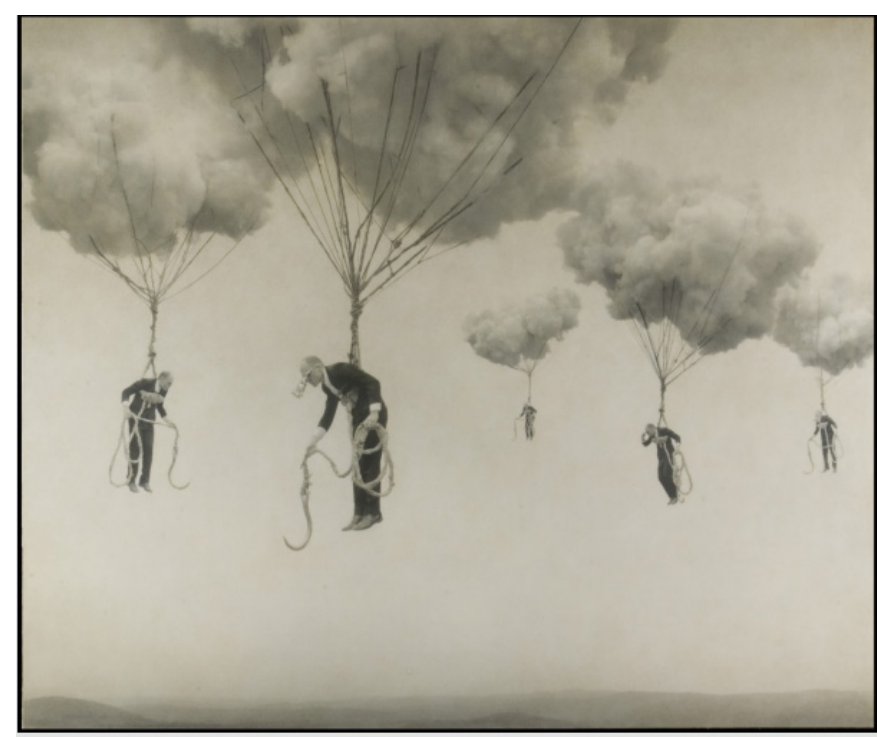

Fonte: https://www.parkeharrison.com/architect-s-brother/procession/394.

O lugar da dramaturgia é justamente este entremeio. Levada pela nuvem, mirando o solo, se equilibrando nesse lugar entre o chão que seus pés não tocam e o céu por onde a nuvem circula e o guia. Sua produção textual é como o anzol de Tethered Sky (também da dupla ParkiHarrison) com o qual tenta se prender ao chão, suspendendo-o levemente.

A dramaturgia vai sempre ter a ver com as fricções dos discursos, das palavras, dos corpos, das matérias. A ela não escapa a companhia daquilo que surge como fio, tecendo os possíveis de um trabaIho cênico. Este tecer não precisa (nem se deseja) ser aleatório. Nem sempre começamos um processo de criação sem nenhuma ideia do que se pretende abordar enquanto "conteúdo semântico". Não se trata aqui de uma ode às sensações ou uma repulsa ao processo de cognição que não cessa de gerar significados, mas, talvez, esses pensamentos sobre as especificidades de uma dramaturgia que performa - ao invés de ser performada por terceiros - queiram dizer algo sobre um momento histórico no qual o excesso de informação, de texto, de discurso, de opinião, nos esteja saturando a cognição. Talvez, já esteja passando da hora de nos atentarmos mais àquilo que o sentido semântico não consegue transmitir. A qualidade de nossas presenças (não só nos espaços de trabalho) parece estar diretamente implicada nisso.

Figura 2 - Tethered Sky, Robert e Shana ParkeHarrison, 2004.

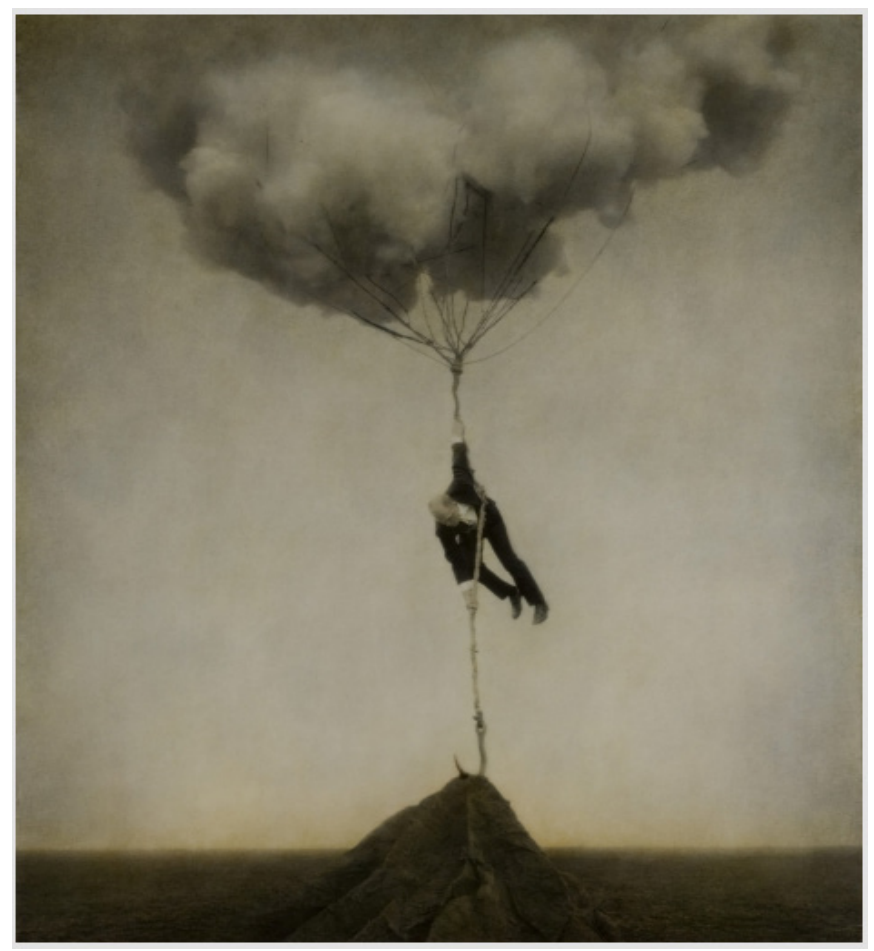

Fonte: https://www.parkeharrison.com/architect-s-brother/burn-season. 


\section{Onde começa um processo de criação?}

Começamos em 2017, no Núcleo Tumulto! de Investigação Cênica, a criar o próximo trabalho da companhia. Tínhamos uma história de fundo, um recorte temático e uma questão norteadora que surgiram em conversas informais a respeito de interesses comuns. Havíamos fundado o grupo em 2013 para um trabalho a partir de um início de pesquisa que eu vinha fazendo. A princípio, o que deveria ser um processo pontual foi se tornando um espaço de experimentação e pesquisa potente para nós. Quase todos trabalháramos juntos no processo de criação citado acima, enquanto ainda fazíamos nossas formações na SP Escola de Teatro. Uma semente dos modos de produção daquele processo havia ficado em nós e percebemos como - trabalhando juntos e sem termos que seguir diretrizes escolares - poderíamos explorar outras possibilidades cênicas e "ver no que dava".

Em 2017, uma das questões que já habitava nossas conversas passava pela linguagem com a qual trabalhávamos e em como direcionar com maior precisão e rigor os nossos estudos e experimentos para um tipo de teatro que faça sentido para nós. As questões da performatividade sempre estiveram presentes, apesar do apreço pelas estruturas narrativas e das questões abertas próprias do teatro épico. Percebemos que em ambos os processos, partíamos da confluência de temas comuns em torno de perguntas para as quais nós não temos e nem teríamos respostas, como um impulso muito maior em gerar perguntas e inquietações do que propriamente propor determinado ponto de vista.

Nesse segundo processo de criação, estávamos então muito mais atentos aos procedimentos que elaborávamos e às soluções que encontrávamos para as questões que surgiam durante os ensaios. Mais uma vez, a dramaturgia foi sendo construída no decorrer dos encontros, a partir das materialidades que surgiam na cena, dos procedimentos propostos por diretor, dramaturga, atores e diretor de arte.

Os procedimentos de criação dramatúrgica foram então sendo catalogados, tanto nos momentos de criação na cena ou com a cena, quanto nos momentos de escrita de materiais textuais que seriam levados como disparadores de respostas cênicas para os atores.

Um destes procedimentos - que se repetiu em cidades distintas e com maior regularidade na criação de materiais textuais vindas de fora do espaço de ensaio - foi a prática de derivas. Algumas com ponto de partida e chegada bem delimitados, outras como caminhadas sem direção ou tempo pré-determinados. Em algumas houve a captação de imagens em fotos e vídeos, em outras a regra era contar somente com as memórias da experiência. Algumas geraram textos em escrita automática em algum ponto da própria deriva, outras ao final, outras ainda geraram materiais textuais produzidos alguns dias depois, centrados na capacidade de descrição a partir da rememoração da prática. As derivas geraram materialidades disparadoras de procedimentos cênicos, de forma que outros modos de produção foram sendo experimentados coletivamente ou em processos nos quais os fragmentos de textos muitas vezes eram somente o gatilho para as experimentações dos atores que partiam então de seus repertórios individuais, das conexões que cada um faz com o processo criativo coletivo.

\section{Narrando um procedimento}

Nasci no Rio de Janeiro em 1984. Tinha dez anos quando vi a seleção brasileira ganhar a Copa do Mundo, o Maradona ser pego no dopping e um zagueiro colombiano de sobrenome Escobar ser assassinado na volta para casa, após sua seleção ser eliminada ainda na primeira fase, tendo perdido para os norte-americanos com um gol contra dele. A imagem de Escobar caído no campo rodou o mundo. De mãos na cabeça, estirado na grama de barriga para cima a mirar o céu. Dias depois, o mesmo corpo estendido, abatido, alvejado com doze tiros na porta de uma casa noturna em Medellín. A versão oficial registra uma briga de bar. Testemunhas dizem que os atiradores eram sicários, funcionários informais do Cartel. Escobar, o boleiro, era jogador do Clube Atlético Nacional, financiado naquela época por outro Escobar, o narcotraficante. 
Foi também nos anos 90, no Rio, que ouvi pela primeira vez os relatos de colegas de escola sobre tiros nas mãos que marcavam os ladrões que roubavam nas imediações dos pontos de venda de drogas. Foi também quando comecei a conhecer o nome de armamentos importados que começavam a circular nas favelas cariocas. Eram comuns as histórias de envolvimentos diretos e indiretos com criminosos e narrativas emocionantes de pessoas que se livravam milagrosamente de assaltos por serem reconhecidas por alguns dos assaltantes, fosse um vizinho, um conhecido de botequim, um aluno da mesma escola dos filhos. Tiroteios passaram a ser frequentes e midiaticamente explorados nos telejornais, enquanto a guerra pela disputa de territórios e clientes era acompanhada tão de perto quanto a telenovela do horário nobre. Sabíamos os nomes das organizações e seus principais chefes e aprendíamos a mapear a cidade pela localização das favelas e seus grupos de domínio. O funk era a trilha sonora e propagava o sentimento, a leitura de mundo e as percepções das pessoas que viviam nas comunidades mais vulneráveis. $E$ todos curtiam o funk, vulneráveis ou não.

Em 1991, nos mudamos, eu, meus pais e três irmãos, para o bairro do Rio Comprido, na Zona Norte. Fomos viver em um apartamento de pouco mais de $40 \mathrm{~m}^{2}$ e a cerca de 50 metros de distância de um dos acessos ao Morro do Turano. A proximidade com o Colégio de Aplicação da UERJ, para o qual minha irmã mais velha tinha acabado de ser aprovada, somou-se a possibilidade de realizar o "sonho da casa própria". Com a ajuda financeira dos meus avós paternos, meus pais compraram o primeiro e único imóvel próprio do nosso núcleo familiar até hoje. Moramos nesse apartamento até dezembro de 1995. Nos mudamos de lá após meu pai sofrer uma tentativa de assassinato. Uma história muito mal contada, com ares de assalto e ajudas sobrenaturais de taxistas angelicais. Era só mais uma das várias histórias que eu e meus irmãos ouvimos, protagonizadas invariavelmente por nosso pai, durante toda nossa infância. Foi nesse mesmo período que nos acostumamos aos frequentes tiroteios no Morro do Turano. Se os bandidos armados nas favelas da Zona Sul davam mais ibope, na Zona Norte e na Baixada a guerra estava fervendo. Da mesma encosta de onde desciam lixo e casas nos dias de temporal, voavam cápsulas de vários calibres que aprendemos a reconhecer pelo som nas noites de tiroteio.

A retomada dessas memórias ajuda a contextualizar as escolhas de agora, mais de duas décadas depois. Elas também introduzem ou ajudam a introduzir um tipo de procedimento adotado de forma mais consciente e objetiva: a busca por materialidades que funcionem como gatilhos psicofísicos para o processo de criação dramatúrgica e para a escrita do texto.

O som de pouco mais de dois minutos de tiroteio gravado por moradores do Turano em 2016 e disponibilizado em plataformas virtuais, tornou-se o primeiro material encontrado com potência de gerar este tipo de deslocamento. Mesmo mais de vinte anos depois e quinhentos quilômetros distante daquela realidade, eu ainda sou capaz de reconhecer determinados calibres e imaginar as armas que atiram de dois em dois ou em rajadas. O estampido seco e o som que ecoa agudo. E isso afeta a minha disposição, o som afeta a postura do meu corpo, minha respiração. Não me recria uma história, uma narrativa, um discurso. Não me rememora palavras. Me leva a viver de novo, de novo e de novo e ainda mais uma vez um estado psicofísico outro, mesmo que hoje eu esteja aqui, escrevendo sobre uma confortável escrivaninha, em um dos bairros mais ricos de uma das cidades mais ricas do país. Depois do primeiro contato com esse material, compartilhei com meus companheiros de criação a seguinte mensagem:

Bem-vindos ao Turano: lar do Menor do Chapa. Algumas das lendas urbanas que já fazem parte do nosso trabalho vêm da época que fui vizinha dessa comunidade. Elas aconteceram entre 1991 ou 1992, não me lembro bem. Preciso confirmar com familiares. Voltei para visitar esse lugar hoje, assim à distância, via google maps. Essa semana, tive uma reunião aqui na Universidade e passamos boa parte do tempo falando sobre gatilhos psicofísicos, treinamento psicofísico e coisas do tipo. Quando a gente é crian- 
ça (e talvez quando é adulto também), as coisas ficam marcadas como uma narrativa que se constrói por muitos meios que não são só discursivos ou de imagens. As memórias têm cheiro e som e tem ainda as que são físicas, corporais, que agem na inclinação da coluna, no ritmo da respiração, na velocidade do pensamento, no foco em determinados sentidos/instintos. Eu já fiz isso outras vezes, mas todas as vezes que eu olho para as imagens dessas ruas e entendo exatamente onde eu vivia é como um gatilho, que traz as histórias, as narrativas, as coisas que eu poderia contar, mas também todas essas outras coisas psicofísicas, como a quantidade de saliva que consigo engolir enquanto faço isso. (Informação verbal) ${ }^{3}$.

A mensagem de texto vinha acompanhada de uma fotografia do mapa que indicava o endereço onde eu vivi e um link para o tal áudio gravado em 2016 por moradores do Turano, durante um tiroteio. A fotografia do mapa e, principalmente, o som, a materialidade sonora daquela sucessão de tiros, se incorporou à coleção de materiais coletados durante o processo.

$\mathrm{Na}$ semana seguinte, no encontro de criação do coletivo, um dos atores nos apresentou uma proposta cênica. Nela, projetava-se a imagem de um navegador de internet aberto, a partir do qual o ator realizava buscas por links de notícias e propagandas a respeito da compra e aluguel de helicópteros a preços similares aos de carros de luxo. Ele zapeava entre links da imprensa e imagens dos modelos desse tipo de aeronave. Em determinado momento, o som dos tiros iniciava. O ator então experimentava uma espécie de coreografia, uma sucessão de movimentos ritmados que hora remetiam aos passinhos de funk, hora a um debater-se descontrolado. Na sequência do som dos tiros, uma playlist do MC Menor do Chapa, autor, dentre outras, do hit $\mathrm{Hu}$ mildade e Disciplina, música lema de um estilo de vida (para o bem ou para o mal) adotado por muitos de nós desta geração carioca. Posteriormente, o ator relatou que os movimentos que experimentou

3 Fala minha no grupo do aplicativo WhatsApp do Núcleo Tumulto! de Investigação Cênica, no dia 30 de abril de 2019 . remetiam às lembranças do debater-se do irmão em um evento de abstinência do uso de cocaína.

\section{Procedimentos de criação}

O percurso dos materiais no processo segue caminhos imprevistos, indeterminados de antemão. O fluxo, a lida com as materialidades cênicas, a criação de atmosferas a partir da presença dos corpos e dos materiais, os estados de presença cultivados por todos os integrantes do núcleo, são indispensáveis para a criação da dramaturgia, assim como a criação dramatúrgica passa a ser indispensável no processo como um todo.

Os materiais surgem daquilo que afeta os integrantes individualmente, são ressignificados a partir do que fazem afetar quando compartilhados e voltam para serem reordenados junto a elementos novos, às fricções propostas tanto no disparador do procedimento, quanto na realização da experimentação cênica. A dramaturgia compõe com essas materialidades uma terceira, novamente textual e que volta para o fluxo de criação coletiva. Esse movimento em espiral leva a um tipo de resultado no qual é quase impossível separar autorias, ainda que o lugar de atuação criativa da dramaturgia esteja assegurado.

\section{Algumas (outras) considerações sobre a prática dramatúrgica e os \\ procedimentos de preparação para a escrita}

Alguns procedimentos podem ser adotados como modos de ativar percepções e deslocar os pressupostos discursivos e pré-conceitos com os quais entramos em um processo criativo. Práticas de concentração, atenção e expansão perceptiva comuns a atuantes se mostram valiosas nesse sentido. Experimentar estar com a atenção voltada às próprias reações psicofísicas que determinados materiais disparam é outro procedimento comum à atuação que pode ativar processos de escrita. Práticas de deriva associadas à escrita automática, práticas de escritura descritiva de imagens, prática de recolhimento de narrativas fortuitas em locais públicos. O que parece ser preponderante é assumir 
que a prática dramatúrgica não deve se basear em fetiches sobre as profissões que envolvem a escrita. Como todo trabalho criativo, requer a elaboração de procedimentos, o rigor com as propostas experimentadas e o comprometimento com o processo de criação de uma maneira menos centralizada nas expectativas de um único sujeito integrante dele.

Mirar os anzóis para o chão e se deixar levar pelo céu no campo-nuvem dos processos de criação - formulando e reformulando modos de estar, de produzir, de trabalhar, e de se relacionar com as pessoas, com as materialidades - , parecem cruciais para a prática de uma dramaturgia que não precisa negar o texto ou a produção textual, mas que se componha em um processo coletivo de fato, em fluxos de criação de materiais e composição cênica que ao fim se tornem obra de um coletivo, sem a prepotência de um posicionamento de autoria que possa assegurar qualquer tipo de status social. Não se faz teatro sozinho. Não se faz teatro só com ideias.

\section{Referências}

FABIÃO, Eleonora. Performance e teatro: poéticas e políticas da cena contemporânea. In: Sala Preta, n. 8, 2008.

LEPECKI, André. Errância como trabalho: sete notas dispersas sobre dramaturgia da dança. In: Dança e Dramaturgias. São Paulo: Nexus, 2016.

GONÇALVES JÚNIOR, Antônio Luiz. O dramaturgista no processo colaborativo de criação cênica: pensamento crítico em gesto. Tese de doutorado. Universidade Estadual de São Paulo. São Paulo, 2019.

GUMBRECHT, Hans Ulrich. Produção de Presença: o que o sentido não consegue transmitir. Rio de Janeiro: Editora Puc, 2010.
Este é um artigo de acesso aberto distribuído sob os termos de uma Licença Creative Commons Atribuição 4.0 Internacional. Disponível em: http://creativecommons.org/licenses/by/4.0.

This is an open-access article distributed under the terms of the Creative Commons Attribution License 4.0 International. Available at: http://creativecommons.org/licenses/by/4.0.

Ce texte en libre accès est placé sous licence Creative Commons Attribution 4.0 International. Disponible sur: http://creativecommons.org/licenses/by/4.0.

Recebido: 09/12/2020

Aceito: 22/04/2021

Aprovado para publicação:27/05/2021 